\title{
Research Progress of Fermentation stater culture on Fermented Sausages
}

\author{
Yuan $\mathrm{Fu}^{1, \mathrm{a}}$, Xiaohui Yan ${ }^{2, \mathrm{~b}}$, Xiaoguang $\mathrm{Wu}^{3, \mathrm{c}}$,Chang $\mathrm{Zhu}^{4, \mathrm{~d}}$, Mengxing \\ $\mathrm{Gou}^{5, \mathrm{e}}$ and Xuejun Liu ${ }^{1, \mathrm{f}, *}$ \\ ${ }^{1}$ College of Food Science and Engineering, \\ Jilin Agricultural University, Changchun, Jilin, 130118, China \\ ${ }^{2}$ Jilin Business and Technology College, \\ Changchun, Jilin, 130507, China \\ 3 Jilin Engineering Vocational College, \\ Food Engineering Branch, Siping, Jilin, 136000, China \\ a2466915394@qq.com, ${ }^{\text {b1079128608@qq.com, }}$, 254228636@qq.com, \\ d14170567@qq.com, ${ }^{\mathrm{d}}$ 122545310@qq.com, ${ }^{\mathrm{f} l i u x u e j u n 63 @ 163 . c o m}$
}

Keywords: fermented sausages; fermentation stater culture;research progress Abstract.Authors summarized fermented sausages the origin, development, species and the role of microorganisms. At the same time, we discussed the fermrntation starterculture and its prospect.

\section{Introduction}

Fermented meat products refers to the livestock and poultry meat in the natural or artificial control conditions, the specific beneficial microbial fermentation or the role of enzymes, resulting in a series of biochemical changes and physical changes made after the processing a class of meat products [1].At present, the fermentation meat products are fermented sausage and fermented ham two categories[2].

Fermented sausage, also known as raw sausage, refers to the minced meat (often refers to pork or beef and animal fat with sugar, salt, starter and spices mixed into the casing, after microbial fermentation made of a stable Microbiological properties and typical fermented scented meat products [3].Almost every country have theirselies fermented sausage, such as Germany has Dauerwurst sausage and so on[4].Traditional fermented sausage flavor unique, nutrient-rich.there are still many shortcomings: the production cycle is long and so an.If you add beneficial microorganisms as a starter during the fermentation process, you can improve the product in all aspects of the effect.Therefore, the starter has become the important role in fermented sausage.

\section{Fermented sausage origin, development and classification}

Fermented sausage has a long history.About 2,000 years ago,the Romans knew with meat and salt, sugar and spice by natural fermentation into a delicious sausage, and it has a longer storage period $[5,6]$.According to the fermentation methods, it can be divided into two historical stages: the 20th century before the natural fermentation; the 20th century, Europe and the United States in order to manually add the fermentation agent as a symbol Modern biotechnology and modern fermentation control technology for fermented sausage development and production [7].Table 1, shows that There are many kinds of fermented sausages, and it is difficult to classify them from the three aspects of dehydration degree, fermentation acidity and origin[8]. 


\section{Microorganisms commonly used in fermented sausages and their effects}

Table2, shows that Microorganisms in the environment are not only large,but also species. No matter what kind of microorganisms do starter, should meet the characteristics of meat fermentation starter cultures. Microbes and their effects in fermented sausages have been studied[9-29].

Table 1 . The commonly Classified methods of fermented sausage

\begin{tabular}{llll}
\hline Basis & Name & Features & Examples \\
\hline Degree of dehydration & Dry & Filtration rate $>30 \%$ & thick sausage \\
& Semi-dry & Filtration rate $>20 \%$ & katenrauchwurst \\
& Quit & Filtration rate $<10 \%$ & Teewurst \\
fermentation acidity & Low acidity & $\mathrm{Ph} \geq 5.5$ & Salami sausage \\
& High acidity & $\mathrm{Ph}<5.4$ & Summer sausage \\
Origin & German & Taste relative to teach acid & Dauerwurst \\
& American & High acid fermentation & Summer sausage \\
& Chinese & Natural dry, low water low & Harbin \\
& & acid & sausage \\
\hline
\end{tabular}

Table 2. Fermented sausage commonly used micro-organisms and its role

\begin{tabular}{cccc}
\hline \multicolumn{2}{c}{ Microbial type } & Name & The role of the sausage \\
\hline Bacteria & Lactobacillus & L.plantarum & Improve the organization of meat; promote \\
& & L.casai & hair color; accelerate drying; inhibit \\
& L.curvatus & pathogen growth and toxin production \\
& L.sake & \\
& streptococcus & Str.acidilactici & \\
& pediococcus & P.acidilactici & \\
& P.pentosaceus & \\
microccus & M.varians & Promote color and stability of color; delay \\
& Staphylococcus & S.carnosus & rancidity; improve flavor \\
Mold & & Candida famata & Delayed rancidity and redness \\
& & P.candidum & Forming a unique appearance, conducive to \\
& & & dry and so on \\
\hline
\end{tabular}

\section{Research of fermented sausage starter cultures}

Starter is contained can play an ideal metabolic activity in fermented substrate of live or dormant microbial agents, and can play in the sausage meat products such as ideal metabolic activity of microbial preparation meat starter cultures [30].

\section{The functional research of starter cultures}

Study on the fermentation starter cultures of good flavor meat. The flavor of fermented meat products is one of the important indexes of its quality decision.Flores, etc. [31] research shows that, Barry saccharomyces strains can restrain by inhibiting lipid oxidation and rancidity substances such as promoting good flavor sausage and so on researches.

Bacteriocin production ability of stduy.Bacteriocincan inhibit the growth of bacteria in the micro-molar concentration, so that organisms are naturally competitive bacteria Advantage. Sarika etc. [32] to study the plant lactobacillus MTCC B1746 and lactic acid milk coccus MTCC B440 production under the condition of calcium alginate embedding fixed bacteriocin ability; Hu Yimin [33] isolated from the traditional fermentation of bacon and sausage in the three strains of Listeria monocytogenes have a significant inhibitory effect of lactic acid bacteria and so on researches.

Reduce the production of biogenic amines.Domestic and foreign related research shows that excessive biological amine will cause harm to the human body [34,35]. Therefore, become the 
focus of the researchers.Baka et al [36,37] found that inoculation of Lactobacillus sake can significantly inhibit the formation of biogenic amines in fermented sausages;Tan Ligong [38] study xylose such as staphylococcus, lactobacillus casei all can effectively reduce the specific content of biogenic amines in fermented sausageand so on researches so on researches.

\section{Conclusions and future outlook}

The domestic research on the fermentation of meat products started later. In recent years, the pace of development is relatively fast but most are still at the laboratory level, the application is very limited. How to produce more fermented sausages with longer shelf life, good quality, high safety and no traditional fermented sausage flavor, appearance and organization characteristics is a new challenge for the current meat fermentation industry. Fermentation stater culture, process improvement and other measures in the fermentation sausage safety, sensory and health quality has an important role in upgrading. The combination of different functional strains will better play the advantages of each strain, the study of different functional strains of synergistic or inhibitory properties to prepare multifunctional compound fermenters will become the focus of future research. With the technological progress of meat processing, the role of various microbes in fermented sausages is still in-depth research, in order to provide the basis for the selection of the best strains of production. We have the confidence and ability to China's fermentation of meat products to overseas.

\section{References}

[1] Qingzhou Li, Hongyu Wang: Food Science.In Chinese. Forum Vol. 32(2011), p. 247-251.

[2] Ning Yang: Meat Industry. In Chinese. Forum Vol. 6(2004), p. 7-9.

[3] Qiang Long, Qiangzhong Nie and Chengguo Liu: Food Science.In Chinese. Forum Vol. 17(2016), p. 263-269.

[4] Jungang Wang, Kaixiong Li and Dongyin Han: Meat Industry.In Chinese. Forum Vol. 6(2009), p. 49-51.

[5] Xueqing Wang, Changwei Ma:Food and Fermentation Industries. In Chinese. Forum Vol. 2(1998), p. 62-67.

[6]Denggong Ma, Chengzhong Wang and Gongming Yu: Journal of Qilu University of Technology. In Chinese. Forum Vol. 22(2008), p. 87-90.

[7] Qiang Long, Qiangzhong Nie and Chengguo Liu: Food Science. In Chinese. Forum Vol. 26(2016), p. 1-11.

[8] Luxananil P, Promchai R and Wanasen S: International Journal of FoodMicrobiology. Sci. ForumVol. 129 (2009), p. 312-315.

[9] Cenci-Goga B T, Ranucci D and Miraglia D: Meat Science. Sci. ForumVol. 78(2008), p. 381-390.

[10] Kotzekidou P, Baka A M and Papavergou E J: Lwt-Food Science and Technology.Sci.Froum Vol. 44(2011), p. 54-61.

[11] Leroy F, Verluyten J and Vuyst L D: International Journal of Food Microbiology. Sci.Forum Vol. 106(2006), p. 270-285.

[12] Bonomo M, Ricciardi A and Zotta T: Meat Science. Sci.Forum Vol. 80(2008), p. 1238-1248.

[13] Lu S L, Xu X L and Zhou G H: Food Control. Sci.Forum Vol. 21(2010), p. 444-449. 
[14] Ruiz-Moyano S, Martín A and Benito M J: Meat Science. Sci.Forum Vol. 83(2009), p . 460-467.

[15] Ammor M, Mayo B: Meat Science. Sci.Forum Vol. 76(2007), p. 138-146.

[16] Maurya P, Borpuzari R, and Nath D: Journal of Food Science and Technology. Sci.Forum Vol. 47(2010), p. 89-93.

[17] AAKA-A: Food and Chemical Toxicology. Sci.Forum Vol. 40(2002), p. 33-41.

[18] Wu Y T, Cui C and Sun W Z: Journal of Food Process Engineering.Sci.Forum Vol. 32(2009), p. 844-854.

[19] Aro J M, Nyam-Osor P and Tsuji K: Food Chemistry. Sci.Forum Vol. 119(2010), p. 279-285.

[20] Casquete R, Benito M J and Martín A: LWT-Food Science and Technology. Sci.Forum Vol. 44(2011), p. 1562-1571.

[21] Ravyts F, Vrancken G and D hondt K: International Journal of Food Microbiology. Sci.Forum Vol. 134(2009), p. 89-95.

[22] Liu Z Y, Li Z H and Zhang M L: International Journal of Food Science \& Technology. Sci.Forum Vol. 45(2010), p. 930-936.

[23] Hüfner E, Hertel C: Current Microbiology. Sci.Forum Vol. 57(2008), p. 490-496.

[24] Baruzzi F, Matarante A and Caputo L: Meat Science. Sci.Forum Vol. 72(2006), p. 261-269.

[25] Andrade M J, Córdoba J J and Casado E M: Meat Science. Sci.Forum Vol.85(2010), p. 256-264.

[26] Paulsen P, Vali S and Bauer F: Meat Science. Sci.Forum Vol. 89(2011), p. 486-490.

[27] Ludemann V, Greco M and Rodríguez M P: LWT-Food Science and Technology. Sci.Forum Vol. 43(2010), p. 315-318.

[28] Castellari C, Quadrelli A M and Laich F: International Journal of Food Microbiology. Sci.Forum Vol. 142(2010), p. 149-155.

[29] Candogan K, Wardlaw F B, and Acton J C: Food Chemistry. Sci.Forum Vol. 116(2009), p. 731-737.

[30] HAMMES W P, HERTEL C: Meat science. Sci.Forum Vol. 49(1998), p. 125-138.

[31] FLORES M, DURA MA and MARCO A: Meat Science. Sci.Forum Vol. 68(2004), p. 439-446.

[32] SARIKA A R, LIPTON A P and AISHWARYA M S: Journal of Applied Sciences Research. Sci.Forum Vol. 8(2012), p. 2197-2202.

[33] Yimin Hu, Zhongyi Lin and Jing Ma: Science and Technology of Food Industry. 34(2013), p. 212-215.(in Chinese)

[34] Xing Wang, Shiling Lu and Xinglian Xu: Food and Fermentation Industries.In Chinese. Forum Vol. 36(2010), p. 133-136.

[35] Shiling Lu, Xinglian Xu and Ruihua Su: Food and Fermentation Industries.In Chinese. Forum Vol. 35(2009), p. 141-146.

[36] BAKA A M, PAPAVERGOU E J and PRAGALLLAKI T: LWT-Food Science and Technology. Sci.Forum Vol. 44(2011), p. 54-61. 
[37] MANGIA N P, TRANI A and DI LUCCIA A: European Food Research and Technology. Sci.Forum Vol. 236(2013), p. 557-566.

[38] Lihong Tan, Wenshui Xia and Chunhui Zhang: Chinese Journal of Public Health. In Chinese. Forum Vol. 21(2005), p. 429-432. 